\title{
COLD TOLERANCE OF AN INBRED LINE POPULATION OF RICE (ORYZA SATIVA L) AT DIFFERENT GROWTH STAGES
}

\author{
${ }^{1}$ Ranawake $\mathrm{AL}^{*},{ }^{2}$ Nakamura C \\ ${ }^{1}$ Faculty of Agriculture, University of Ruhuna, Mapalana, Kamburupitiya, Sri Lanka \\ ${ }^{2}$ Graduate School of Science and Technology, Kobe University, Japan1-1 Rokkodai, Nada-ku, Kobe, Japan
}

Accepted: 18 November, 2011

\begin{abstract}
Indica rice cultivar Hokuriku142, japonica rice cultivar Hyogokithanishiki and a recombinant inbred line population involving these cultivars were evaluated for cold tolerance at germination, postgermination and seedling stages. For each experiment 10 replicates were arranged with 20-40 seeds per replicate. At germination stage, cold stress was applied at $20^{\circ} \mathrm{C}$ and $15^{\circ} \mathrm{C}$ and the number of germinated seeds was counted. Post-germination stage cold tolerance was evaluated on 4-day germinated seeds byholding them at $4^{\circ} \mathrm{C}$ for 1-12 days and gained hypocotyl length was measured after a 4-day recovery period at normal growth conditions. To assess the seedling stage cold tolerance 1-week-old seedlings were maintained at $4^{\circ} \mathrm{C}$ for 1-7 days and green plant height was measured after a 5-day recovery period. In all growth stages Hyogokithanishiki showed higher degree of cold tolerance than Hokuriku. Recombinant inbred line population showed normal distribution curves for germination and postgermination stage cold tolearance with transgressive segregants for both higher and lower levels than the parents. At the seedling stage, the inbred populations showed a skew towards the susceptible cultivar but there were two transgressive segregants for greater cold tolerance than Hyogokithanishiki. Identification of such significant differences in the two parental rice cultivars and distribution of the character across the range of different tolerance levels with transgressive segregation indicates that this population is useful for the development of cold tolerant rice cultivars and to understand the basis of the cold regulation of rice using molecular tools.
\end{abstract}

Key words: Cold Tolerance, Rice

\section{INTRODUCTION}

Cold stress at the seedling stage and high temperatures at flowering stage occur in the regions of subtropics where rice is cultivated. In the temperate regions rice growth is constrained by the limited period that favors growth where it needs optimum temperature between $25^{\circ} \mathrm{C}$ to $35^{\circ} \mathrm{C}$ and temperatures below this often result in poor seedling vigor (Reyes et al. 2003). Temperatures below $25^{\circ} \mathrm{C}$ would cause growth abnormalities in temperate and high-elevated tropical rices (Fujinoet al. 2004; Sthapitet al. 1998). Therefore development of rice cultivars with considerable level of cold tolerance is needed.

Continuous selection for high yield can result in the narrowing down of gene pool while it reaches a yield plateau. In Korea rice yield plateau has prevailed for twenty years regardless of many efforts by rice breeding programs (Moon et al. 1994). One way of overcoming this problem is to introgress Indica and Japonica gene pools (Dilday 1990).

\footnotetext{
*Corresponding author: lankaranawake@agbio.ruh.ac.lk
}

Genetic divergence studies among 17 rice varieties known to possess some degree of cold tolerance at different growth stages revealed that Indica group has moderate to low degree of cold tolerance while the Japonica group displayed high degree of cold tolerance (Khush et al. 1999). Kwon et al. (2002) demonstrated that Amplified Fragment Length Polymorphic (AFLP) markers are not useful for predicting heterosis for cold tolerance in Japonica hybrids but progenies of Indica and Japonica crosses provide genetic resources for development of cold tolerance of rice (Miura et al. 2001; Andaya and Mackill 2003a, 2003b; Saito et al., 2004; Andaya and Tai 2006, 2007; Zhang et al. 2005a).

Conventional breeding is a slow process for generating crop varieties with improved tolerance to stress conditions (Wu and Ho 1999). Incompatibility in crosses between distantly related plant species and limited germplasm resources for stress tolerance are also barriers encountered in conventional breeding. Integration of compatible molecular biological methods with conventional breeding 
programs accelerates the process of varietal improvement of rice. Among those techniques, Quantitative Trait Loci (QTL) analysis is a useful tool to dissect responsive genes for desirable characters of populations with enough phenotypic variance.

QTL analysis of rice using progenies derived from crosses between Indica and Japonica cultivars has been performed by many researchers. Andaya and Tai (2006) used a population derived from Japonica rice cultivar M202 and Indica rice cultivar IR50. Lou et al. (2007) used a population derived from a cross between Japonica cultivar AAV 002863 and Indica cultivar Zhenshan 97B. A cross between Indica landrace cultivar Kunmingxiaobaigu and a Japonica rice cultivar Towada was used by Dai et al. (2004) for analysis of cold tolerant QTLs at booting stage. Fujino and Sekiguchi (2005) used Japonica crosses successfully to detect heading date QTLs in rice grown in northern limit for cold tolerant and long day-length responsive QTLs. Takeuchi et al. (2001) also used a Japonica X Japonica cross for QTL detection at booting stage. Other than Japonica X Indica crosses, some investigators used double haploid populations (Qian et al. 2000; Gao et al. 2007) and introgression lines (Saito et al.2004).

Cold tolerant QTLs at seed germination, vegetative and booting stages have also been identified in different populations (Fujino et al. 2004; Saito et al. 2001; Andaya and MacKill 2003a, 2003b; Andaya and Tai 2006 2007, Zhang et al. 2005a). Cold tolerant QTLs are different in different populations and are varied with the developmental stage in the same population of the plants as cold tolerance is developmentally regulated and growth stagespecific (Foolad 2001). The cold tolerance at one developmental stage is therefore not necessarily correlated with the tolerance at other stages (Foolad, 2001). It has been demonstrated that cold tolerance at the vegetative growth stage is independent of that at the reproductive growth stage of rice (Kaw et al. 1986). Thus, the development of methods for evaluation of cold tolerance for each developmental stage of rice life cycle need to be identified by careful examination of morphological changes in each developmental stage under the stress (Foolad 2001).
Better seedling establishment is very much responsible for the vigorous growth in vegetative stage with suitable green canopy, which is an advantageous character for higher starch production in later reproductive phase. The optimum temperatures for rice germination and early seedling growth were reported as $25-35.8^{\circ} \mathrm{C}$ and the presence of some QTLs for cold tolerance at seedling stage of rice have been published by Yan et al. (1999), Andaya et al. (2002), Zhang et al. (2005a), Qian et al. (2000), Misawa et al. (2000), Lou et al. (2007) and Andaya and Tai (2007) in different populations.

Seedling vigour is a parameter to evaluate plant's withstanding strength against any kind of stress conditions. Shoot length wasreported to be the best variable determinant ofseedling vigour (Peterson et al.,1978). Redo na and Mackill (1996) found that shoot weight, shoot length and coleoptiles length were the best determinants to predict greenhouse and field seedling vigour of rice. In a study carried out by Zhang et al.(2005b)shootlength was the only character associated with all of the five seedling vigour QTLs identified at different temperatures considering shoot length, germination rate, root length and dry matter production of the inbred line population, thus providing strong support for the suggestion that shoot length is the best predictor of seedling vigour in rice. However they proposed that multiple related traits should be considered in experiments for any kind of QTL mapping, which will reveal genetic relationships among such complex traits. In the present study two Japonica and Indica parental rice cultivars were evaluated for cold tolerance at germination, post germination, and seedling stage and the methodologies adapted to evaluate these parents were applied to evaluate 163 inbred line population derived from these parents. The results showed the suitability of the population for QTL analysis at germination, post germination and seedling growth stages.

\section{MATERIALS AND METHODS}

A recombinant inbred line (RIL) population $\left(\mathrm{F}_{6}\right.$ generation) of 163 lines derived from a cross between cold tolerant Japonica rice cultivar Hyogokithanishiki, and a cold susceptible 
Indica rice cultivar Hokuriku-142 was used. Hokuriku-142 (Hokuriku) was bred from a cross between a Korean cultivar, 'Milyang 21' and an IRRI line ' IR-2061-214-31' in Hokuriku Agricultural Experimental station, Japan. Inbred line populations were advanced according to the single seed descent method and were selfed at each generation.

\section{Germination stage cold tolerance}

Dormancy broken surface sterilized seeds were maintained at $20^{\circ} \mathrm{C}$ for two days and then temperature of the incubator was changed to $15^{\circ} \mathrm{C}$. Rate of germination of two cultivars were measured daily. Seeds those hypocotyl lengths were greater than the seed length; approximately $5 \mathrm{~mm}$ were considered as germinated seeds. Considering the results of experiment with the two parental rice cultivars, initial two-day period at $20^{\circ} \mathrm{C}$ and 12 days at $15^{\circ} \mathrm{C}$ was applied to the inbred line population and the number of germinated seeds were counted at the end of the experiment.

\section{Post germination stage cold tolerance}

Dormancy broken, surface sterilized seeds of parent cultivars were germinated at $35^{\circ} \mathrm{C}$ for 4 days. Cold stress was applied at $4^{\circ} \mathrm{C}$ for 12 days to 4-day-oldgerminating seedlings, followed by a 4-day recovery period at $25^{\circ} \mathrm{C}$. Gained shoot length during the cold stress and the recovery period was used as a parameter for evaluating the level of cold tolerance (Fig.1).For the RIL population, a 5-day cold treatment at $4^{\circ} \mathrm{Cwas}$ applied for the evaluation of cold tolerance at post germination stage. Twenty seeds of each line were subjected to cold tresses in separate experiments and experiment was repeated three times. Experiment was arranged according to a complete randomized design and data was recorded on the $5^{\text {th }}$ day of the recovery period followed by the cold stress.

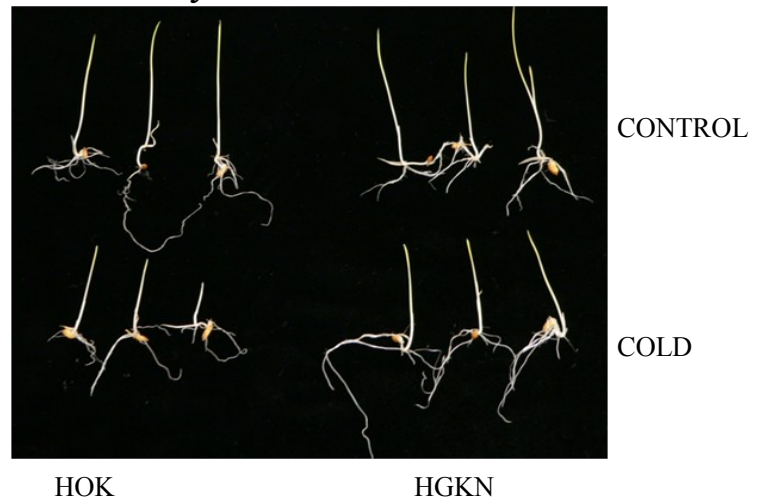

Figure. 1 Germinated seedlings of two parental rice cultivars under control condition and under cold stress at post germination stage (HOK -Hokuriku142, HGKN - Hyogokithanishiki)

\section{Seedling stage cold tolerance}

Breakage of dormancy and uniform germination were achieved by maintaining surface-sterilized seeds at $35^{\circ} \mathrm{C}$ for 6 days in distilled water. On the 6th day, germinating seeds were planted in Petridishes and maintained at $25^{\circ} \mathrm{C}$ for one week under a 16hour photoperiod (normal growth conditions). On the 7th day, seedlings (13-day -old) were transferred to $4^{\circ} \mathrm{C}$ for cold stress and maintained up to 7 days. Green shoot length was measured on the 5th day of the recovery period under normal growth conditions and the survival rates of the two cultivars under cold stress at seedling stage were calculated.

Based on the results of parent cultivars, 3-day cold stress at $4^{\circ} \mathrm{C}$ was used for scoring the cold tolerance in RILs. The level of cold tolerance was evaluated according to a fivepoint rating scale (Fig. 3 ) on the $5^{\text {th }}$ day of the recovery period.

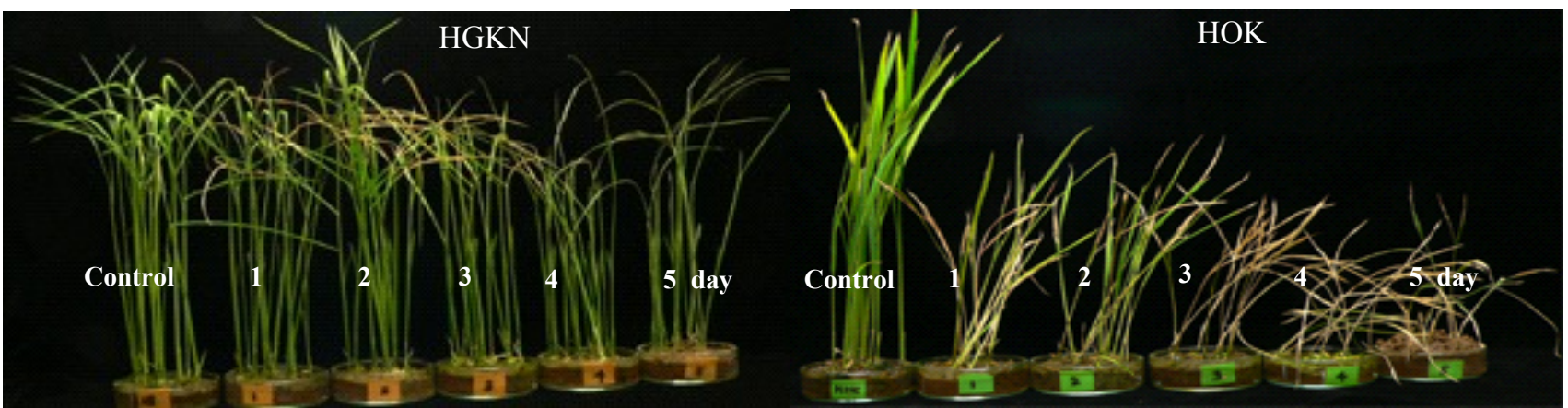

Figure 2 Two rice cultivars in recovery period, stressed at $4^{\circ} \mathrm{C}$ cold stress for 1: 1-day, 2: 2-day, 3:3-day, 4: 4-day, 5: 5-day cold stress period (HOK - Hokuriku-142, HGKN - Hyogokithanishiki) 


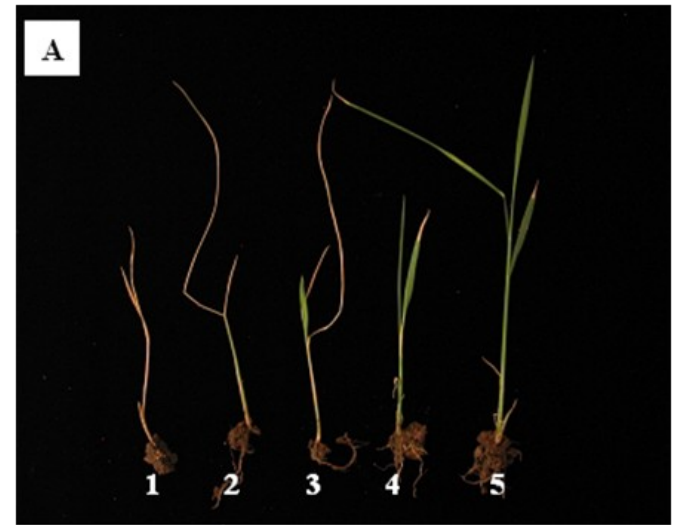

Figure 3 Five point rating scale used for the evaluation of inbred line population.1- the whole seedling became completely withered, $2-1$ st and 2 nd leaves became withered but the stem remained green, 3 - only the stem and 3rd leaf remained green, 4 - the stem and two leaves remained green, and 5 - normal growth with all the leaves remained

\section{Analysis of correlation}

Pair wise correlation analysis was performed to understand the relationship in cold tolerance at different growth stages in rice.

\section{RESULTSAND DISCUSSION}

\section{Germination stage cold tolerance}

In the present study seeds started germination at $20^{\circ} \mathrm{C}$, while at $15^{\circ} \mathrm{C}$ seed germination was retarded. With time, seeds of Hyogokithanishiki continued germination while those of Hokuriku stopped further hypocotyls protrusion. On the 12th day at $15^{\circ} \mathrm{C}$, a significant difference in germination percentage between the two parental rice cultivars could be seen. Hokuriku recorded 0 $8 \%$ germination at low temperature and its average germination at low temperature was $2.6 \%$. Hyogokithanishiki recorded $66.7-91.6 \%$ germination at low temperature, with an average of $77.3 \%$ (Fig.4). Most studies performed at germination stage in rice under controlled temperature to identify the variability and genotype characterization showed that genotypes belonging to Japonica subspecies are more cold tolerant than Indica (Li et al., 1981; Cruz \& Milach, 2004). The reason for this difference would be that the Japonica rice cultivars evolved in temperate regions while the evolution of Indica rice cultivars has taken place in tropical climates. At the early seedling stage and seedling stage Japonica was better than Javonica, Indica and wild species while at panicle development and flowering stagesJavonica was better than the other types (Visperas and Vergara, 1981). The authors showed not only the varietal difference in cold tolerance on basis of origin but also the stage of growth of the plant.

Inbred line population showed normal distribution for low temperature germination and many lines recorded higher germination percentage at low temperature than that of Hyogokithanishiki (Fig. 4). Transgressive segregants were recorded in both directions showing that both parents possess cold tolerant alleles and therefore this population can be easily used for QTL analysis in rice cold tolerance at germination stage.

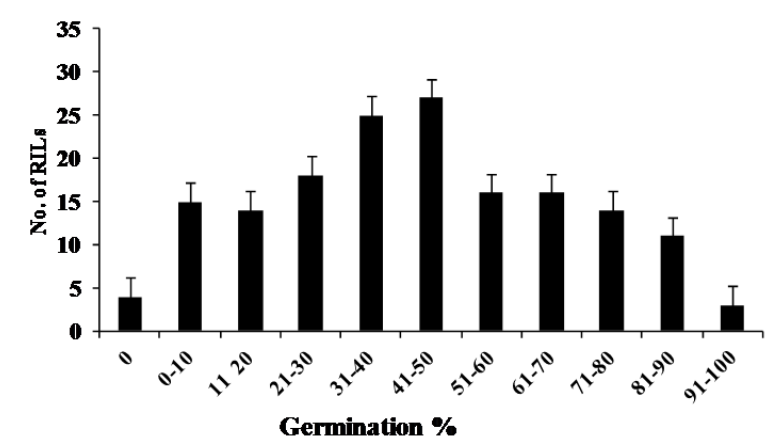

Figure 4. Population distribution of low temperature germination rate in the recombinant inbred population and parent cultivars. Two-day cold period at $20^{\circ} \mathrm{C}$ followed by 12 days at $15^{\circ} \mathrm{C}$ was applied to evaluate inbred line population for cold tolerance. Bars indicate standard deviations. HOK Hokuriku-142, HGKN - Hyogokithanishiki

Evaluation of populations for low temperature germinability has been widely practiced in different populations and different low temperature stresses for different durations such as $15^{\circ} \mathrm{C}$ for seven-days (Fujino 2004), $15^{\circ} \mathrm{C}$ for four-days (Miura et al. 2001 ), $15^{\circ} \mathrm{C}$ for 6 days (Liang et al. 2006), $13^{\circ} \mathrm{C}$ for 28 days (Cruz et al. 2004), $14^{\circ} \mathrm{C}$ for $7-17$ days (Zhi et al. 2006), $13^{\circ} \mathrm{C}$ for 30 days (Cruz et al. 2006) and $17^{\circ} \mathrm{C}$ for 7 days (Stapit and Witcombe, 1998) have been used. This procedure has not been standerdised, and needs to be adjusted for each population. Optimum temperature range for rice germination lies between $20-35^{\circ} \mathrm{C}$, and the temperature of $10^{\circ} \mathrm{C}$ is cited as the minimum critical value below which rice does not germinate (Yoshida 1981b). Seeds were submitted to temperatures varying from 10 to $25^{\circ} \mathrm{C}$ for periods of three to thirty five days 
and parameters such as germination percentage, rate of germination, and coleoptile and radicule length (Maya 1988; Srinivasulu \& Vergara 1988; Bertin et al. 1996; Sthapit \& Witcombe 1998) have been used in cold tolerant assessment at germination stage.

Germination is divided into three phases: imbibition, activation and post- germination growth (Yoshida 1981a). The greatest effect of cold temperature during germination has been attributed to the imbibition phase, considered to be the most sensitive (Cruz et al., 2004). In the present study, $20^{\circ} \mathrm{C}$, a comparatively mild cold stress was given at the initial stage of germination and a moderatelysevere $15^{\circ} \mathrm{C}$ cold stress was given at activation period. However, Yoshida (1981b) reports that the greatest influence of temperature on germination occurs in the subsequent phases of activation and growth of coleoptile and radicule. However, reports on the effect of temperature on the germination period of rice is contradictory and the existence of different physiological mechanisms involved with cold tolerance at the vegetative period is an indication that even at the germination phases, different processes may also be affected implying in different tolerance mechanisms. Massardo et al. (2000) demonstrated that higher metabolic rates and less oxidative damage were the reason for the tolerance of genotypes to cold temperature during germination in Oat.

\section{Post-germination stage cold tolerance}

In our bioassay HOK showed a higher shoot length gain until the $4^{\text {th }}$ day of cold stress than HGKN, whereas after the $5^{\text {th }}$ day of cold stress, HGKN recorded a greater value than HOK (Fig.5). This would be the reason that HGKN acquired cold acclimation by the $5^{\text {th }}$ day of cold treatment while HOK failed. Increase in freezing tolerance upon exposure to low non-freezing temperatures is called as cold acclimation (Thomashow 1999). Kim and Tai (2011) also showed that some Indicas provide useful genes for improving seedling cold tolerance in Japonicas.

After the $5^{\text {th }}$ day of cold stress, shoot gain decreased in both parents, but Japonica

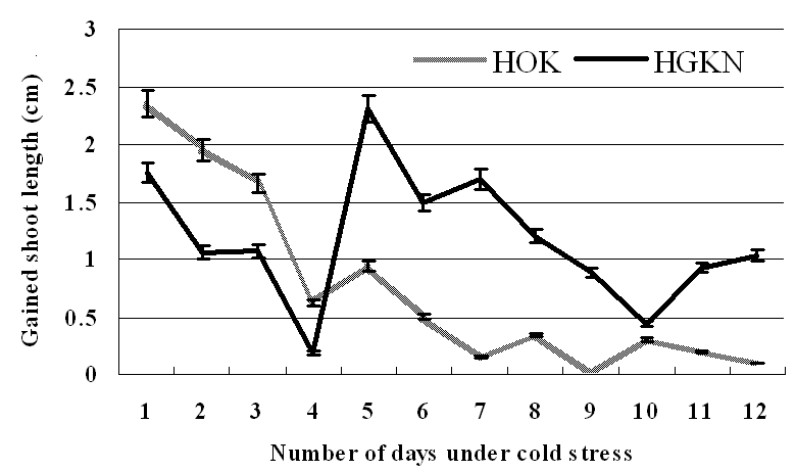

Figure 5. Gained shoot length of two parental rice cultivars after different days of cold stress at $4^{\circ} \mathrm{C}$ and recovered at $35^{\circ} \mathrm{C}$ in the dark for 4-days at post germination stage. The values are averages of three replicates and each replicate consisted of twentyseeds. HOK - Hokuriku-142, HGKN Hyogokithanishiki

parent, HGKN maintained higher mean values until the end of the experiment, i.e. 12-day cold stress. This can be explained by the fact that Japonica cultivars, which are grown in both tropical and temperate zones, are typically more cold tolerant than Indica cultivars, which are found mostly in tropical lowland areas (Glaszmann et al. 1990; Mackill and Lei1997; Baruah et al. 2009).

Populations were studied for post germination stage or early seedling stage cold tolerance by Zhang et al. (2005a) and Yan et al. (1999) using different conditions than what we applied. Specific procedures for the particular population need to be selected through series of preliminary studies for the better exploration of the population specific characters.

The frequency distribution of RILs showed9 different classes based on the gained shoot length after 5-day cold stress (Fig.6). The gained shoot length in RILs showed a nearly normal distribution, indicating that this trait is under polygenic control. A number of transgressive segregants showing either smaller or larger values than those of the parents were observed after the 5-day cold stress emphasizing the contribution of both parents to cold tolerance of inbred line population. More vigorous low temperature germinability than the recurrent parent was recorded in several studies (Fujinoet al. 2008; Iwata and Fujino 2010). 


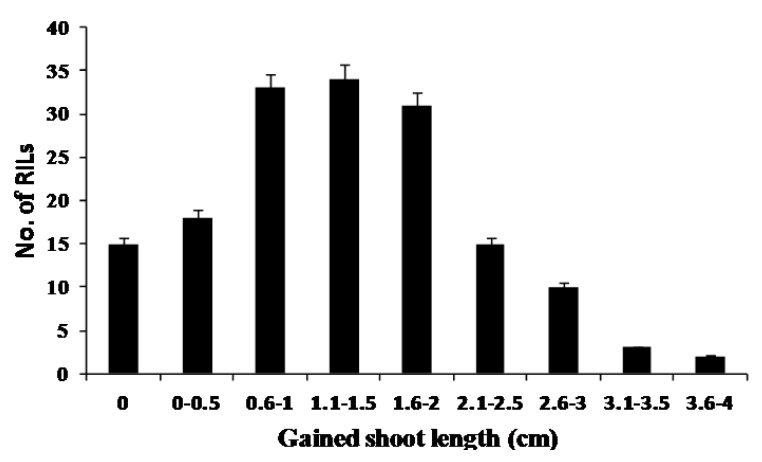

Figure 6. Frequency distribution of inbred line population according to the average gained shoot length after cold stress at $4^{\circ} \mathrm{C}$ for 5-days and recovered at $35^{\circ} \mathrm{C}$ in the dark for 4days. Bars indicate standard deviations. HOK - Hokuriku-142, HGKN - Hyogokithanishiki

\section{Seedling stage cold tolerance}

Visual assessment of morphological characters following direct exposure to low temperatures is the most common method of evaluation of cold tolerance at the seedling stage (Bertin et al. 1996). Cold tolerance at the seedling stage in rice has mainly been studied at temperatures ranging from 4 to $10^{\circ} \mathrm{C}$ (Qian et al. 2000; Andaya and Mackill 2003a; Zhang et al. 2005a, Misawa et al. 2000). In each case different bio assays have been applied and different indices were evaluated such as leaf chlorosis/discoloration (Kwak et al. 1984; Andaya and Mackill 2003a; Han et al. 2004), withering, necrosis, mortality (Nagamine 1991; Andaya and Mackill 2003a; Lou et al. 2007), reduced seedling vigor (Zhang et al. 2005b), and decreased recovery of shoots (Baruah et al. 2009). In the present study length of green shoot was considered as the parameter for the estimation of cold tolerance.

All seedlings of the Indica cultivar HOK turned brown and died at the $5^{\text {th }}$ day of recovery period after 3 days of cold stress, whereas all seedlings of the Japonica cultivar HGKN retained green shoots with their mean length of $17.4 \mathrm{~cm}$ under the same stress condition (Fig.7). The results showed a significant difference in the two cultivars for cold tolerance at the seedling stage from 3 day cold stress onward(Fig.7). To evaluate the inbred line population derived from these two parents, an arbitrary rating scale was developed considering the green shoot length of the recovered seedlings (Fig. 3)

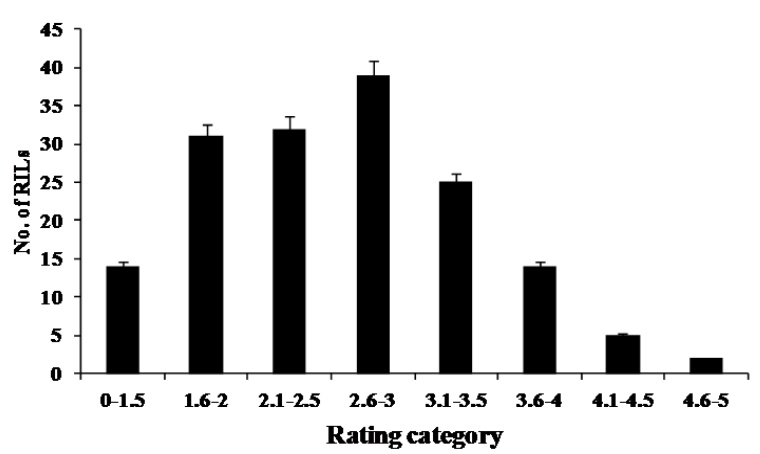

Figure 7. Frequency distribution of cold tolerance ratingsat the post-germination stage of the inbred line population after the cold treatment. The ratings range from 5 (cold tolerant) to 1 (susceptible). Five point rating scale used for the evaluation of inbred line population is given in Fig.3.Parent cultivars: HOK - Hokuriku-142, HGKN - Hyogokithanishiki.

For post-germination stage cold tolerance RILs showed a little left-skewed distribution towards cold susceptibility (Fig. 7, Fig.3). HGKN showed an average rating of 4.4 , while that of HOK was 1.5 (Fig. 7). Two RILs were showed higher level of cold tolerance than the cold tolerant parent HGKN.

Analysis of variance demonstrated significant variability in ratings between the lines but no significant differences within the line, indicating that seedling response to the cold treatment was homogeneous within each line.

Correlation analysis between growth stage and cold tolerance showed a positive but weaklysignificant (at 0.0145 significance level) correlation (correlation coefficient $=0.1934$ ) between post germination and seedling stage but there was no correlation between other growth stages. Li et al. (1981) also reported a significant positive correlation in cold tolerance between early seedling stage and seedling stage in rice. This may indicate the existence of similar cold tolerance mechanisms in early seedling stage and seedling stage but existence of different cold tolerance mechanisms in cold tolerance at germination stage.

\section{CONCLUSION}

For the evaluation of germination stage cold tolerance, 2-day cold stress at $20^{\circ} \mathrm{C}$ followed by a 12-day cold stress at $15^{\circ} \mathrm{C}$ and continuously in dark condition is appropriate 
for a population derived from Hyogokithanishiki and Hokuriku.

A cold stress for 5 days at $4^{\circ} \mathrm{C}$ for 4-day germinated seedlings at $35^{\circ} \mathrm{C}$ is suitable for the evaluation of post-germination stage cold tolerance and 3-day cold stress at $4^{\circ} \mathrm{C}$ followed by a 5 day recovery period is suitable for scoring the level of cold toleranceat the seedling stage.

This protocol may be applied to a larger set of rice accessions in identifying useful materials for breeding and genetic studies of germination, post-germination and seedling cold tolerance.

\section{ACKNOWLEDGEMENTS}

The first author wishes to acknowledge Monbukagakusho (Ministry of Education, Culture, Sports, Science and Technology, Government of Japan) for the financial support for postgraduate studies in Japan and Prof. Shinya Yoshida, Hyogo Institute of Agriculture, Forestry and Fishery, Japan for providing plant materials, Prof. Naoki Mori and Prof. T. Ishii for technical support and Prof. Ranjith Pathirana for critical reviewing of manuscript.

\section{REFERENCES}

Ahn S, Anderson JA, Sorrells ME and Tanksley SD 1993 Homoeologous relationship of rice, wheat and maize chromosomes. Mol. Gen. Genet. 241: 483-490.

Andaya VC and Mackill DJ 2003a Mapping of QTLs associated with cold tolerance during the vegetative stage in rice. J. Exp. Bot. 54: 25792585.

Andaya VC and Mackill DJ 2003b QTLs conferring cold tolerance at the booting stage of rice using recombinant inbred lines from a japonica X indica cross. Theor. Appl. Genet. 106:1084-1090.

Andaya VC and Tai TH 2006 Fine mapping of the qCTS12 locus, a major QTL for seedling cold tolerance in rice. Theor. Appl. Genet. 113:467475.

Andaya VC and Tai TH 2007 Fine mapping of the qCTS4 locus associated with seedling cold tolerance in rice (Oryza sativa L.). Mol. Breed. 20: 349-358.

Baruah AR, Ishigo-Oka N, Adachi M, Oguma Y,
Tokizono Y, Onishi K and Sano Y 2009 Cold tolerance at the early growth stage in wild and cultivated rice. Euphytica. 165:459-470.

Bertin P, Kinet JM and Bouharmont J 1996 Evaluation of chillingsensitivity in different rice varieties. Relationship between screeningprocedures applied during germination and vegetative growth.Euphytica. 89: 201-210.

Cruz RPD and Milach SCK 2004 Cold tolerance at the germination stage of rice: methods of evaluation and characterization of genotypes.Sci. Agric. (Piracicaba, Braz.). 61-1: $1-8$.

Cruz RPD, Milach SCK and Federizzi LC 2006 Inheritance of rice cold tolerance at germination stage. Genetics and Molecular Biology. 292: 314-320.

Dai L, Lin X, Ye C, Ise K, Saito K, Kato A, Xu F, $\mathrm{Yu} \mathrm{T}$ and Zhang D 2004 Identification of quantitative trait loci controlling cold tolerance at the reproductive stage in Yunnan landrace of Rice. Kumingxiaobaigu. Breed. Sci. 54: 253258.

Dilday RH 1990 Contribution of ancestral lines in the development of new cultivars of rice. Crop Sci. 30: 905-911.

Foolad MR, and Lin GY 2001 Relationship between cold tolerance during seed germination and vegetative growth in tomato. Analysis of response and correlated response to selection, J. Amer. Soc. Hort. Sci., 126: 216-220.

Fujino K and Sekiguchi H 2005 Identification of QTLs conferring genetic variation for heading date among rice varieties at the northern-limit of rice cultivation. Breed. Sci. 55: 141-146.

Fujino K, Sekiguchi H, Matsuda Y, Sugimoto K, Ono K and Yano M 2008 Molecular identification of a major quantitative trait locus, qLTG3-1, controlling low-temperature germinability in rice. Proc. Natl. Acad. Sci. USA 105: 12623-12628.

Fujino K, Sekiguchi H, Sato T, Kiuchi H, Nonoue Y, Takeuchi Y, Ando T, Lin SY and Yano M2004 Mapping of quantitative trait loci controlling low-temperature germinability in rice(Oryza sativa L.). Theor.Appl.Genet. 108:794-799.

Fujino KA 2004 Major gene for low temperature germinability in rice (Oryza sativa L.). Euphytica. 136: 63-68.

Gao YM and Zhu J 2007 Mapping QTLs with digenic epistasis under multiple environments and predicting heterosis based on QTL effects. Theor. Appl. Genet. 115: 325-333.

Glaszmann JC, Kaw RN and Khush GS 1990 Genetic divergence among cold tolerant rices (Oryza sativa L.). Euphytica. 45: 95-104.

Iwata N and Fujino K 2010 Genetic effects of 
major QTLs controlling low-temperature germinability in different genetic backgrounds in rice (Oryza sativa L.). Genome. 53: 763-768.

Kaw RN and Khush G S 1986 Combining ability for low-temperature tolerance in rice. Proceedings International Rice Genetics Symposium, Los Banos, Philippines, 593-612.

Khush GH and Brar DS 2002 Biotechnology for rice breeding: Progress and potential impact. Proceedings of Twentieth session, The international rice commission, Bangkok, Thailand.

Kim SI Andaya VC Tai TH (2011) Evaluation of seedling cold tolerance in rice cultivars: a comparison of visual ratings and quantitative indicators of physiological changes Euphytica 178:437-447

Kwak TS, Vergara BS, Nanda JS and Coffman WR 1984 Inheritance of seedling cold tolerance in rice. SABRAO J. 16: 17-32.

Kwon SJ Ahn SN Jeong EG Jeon YH Hwang HG Choil HC and Moon HP 2002 Relationship between genetic divergence and hybrid performance in japonica rice grown in a cold water-irrigated field. Euphytica 128: 389-396.

Li TG, Vispera RM and Vergara BS 1981 Correlation of cold toleranceat different growth stages in rice. Acta Botanica Sinica. 23: 203207.

Liang C, Jun LQ, Xiu SZ, Zhong XY, Qiao YX and Jun LL 2006 QTL mapping of low temperature on germination rate of rice. Rice Sci. 13-2: 93-98.

Lou Q, Chen L, Sun Z, Xing Y, Li J, Xu X, Mei M, Luo J and Luo ML 2007 A major QTL associated with cold tolerance at seedling stage in rice (Oryza sativa L.). Euphytica. 158: 87-94.

Mackill DJ and Lei X 1997 Genetic variation for traits related to temperate adaptation of rice cultivars. Crop Sci. 37: 1340-1346.

Massardo F, Corcuera L and Alberdi M2000 Embryo physiological responses to cold by two c u $1 \mathrm{tivars}$ of $\mathrm{Oat}$ d uring germination.CropScience.40: 1694-1701.

Maya OIM1988 Identificacion de metodologias para la evaluacion detolerancia a temperaturas bajas en arroz (Oryza sativa L.) Palmira:Universidade Nacional de Colombia. Facultad de CienciasAgropecuarias, 123, Monografia, Graduação.

Misawa S, Mori N, Takumi S, Yoshida S and Nakamura C 2000 Mapping of QTLs for low temperature response in seedlings of rice (Oryza sativa L.). Cereal Res. Communi. 28: 33-40.

Miura K, Lin SH, Yano M and Nagamine T 2001 Mapping quantitative trait loci controlling low temperature germinability in rice (Oryza sativa L.). Breed. Sci. 51: 293-299.
Moon HP Heu MH Kim CH 1994 Hybrid rice research in the Republic of Korea. In:S.S. Virmani (ed.) Hybrid rice technology: New developments and Future prospects International Rice Research Institute, Phillipines217-226.

Morishima Hand Oka HI1981 Phylogenetic differenciation of cultivated rice XXII. Numerical evaluation of the indica-japonica differenciation.jpn.J.Breed. 31: 402-413.

Murray MG and Thompson WF 1980 Rapid isolation of high molecular weight DNA. Nucl. Acid Res. 8: 4321-4325.

Nagamine T 1991 Genetic control to tolerance to chilling injury in rice (Orza sativa L.). Jap. J. Breed. 41: 35-40.

Nakagahra M, Okuno K and Vaughan D 1997 Rice genetic resources: history, conservation, investigative characterization and use in Japan. Plant Mol. Biol. 35: 69-77.

Peterson ML, Jones DB and Rutger JN 1978 Cool temperature screening of rice lines for seedling vigor. II Riso, Ente Nazionale Risi, Milan, Italy. 27: 269-274.

Qian Q, Dali Z, Ping H, Xianwu Z, Ying C and Lihuang Z 2000 QTL analysis of rice seedling cold tolerance in a double haploid population derieved from anther culture of a hybrid between indica and japonica rice. Chinese Sc. Bull. 45: 448-453.

Redo na ED and MackillDJ 1996 Mapping quantitative trait loci for seedling vigor in rice using RFLPs. Theor Appl Genet 92: 395-402

Reyes BG, Myers SJ, McGrath JM 2003 Differential induction of glyoxylatecycle enzymes by stress as a marker for seedling vigor in sugar beet (Beta vulgaris) Molecular Genetics \& Genomics 269: 692 - 698 .

Saito K, Harano-Saito Y, Maruyama-Funatsuki W, Sato Y and Kato A 2004 Physical mapping and putative gene identification of a quantitative trait locus $C t b 1$ for cold tolerance at the booting stage of rice. Theor. Appl. Genet. 109: 512-522.

Saito K, Miura K, Nagano K, Hayano-Saito Y, Araki H and Kato A 2001 Identification of two closely linked quantitative trait loci for cold tolerance on chromosome 4 of rice and their association with anther length. Theor. Appl. Genet. 103: 862-868.

Srinivasulu K and Verrgara BS 1988 Screening of upland and shortduration rice varieties for cold tolerance at seedling emergence stage. Biological Sciences.25: 87-90.

Sthapit BR and Witcombe JR 1998 Inheritance of tolerance to chilling stress in rice during germination and plumule greening. Crop Sci. 38: 660-665.

Takeuchi Y, Hayasaka Y, Chiba B, Tanaka I, Shimano T, Yamagishi M, Nagano K, Sasaki T 
and Yano M 2001 Mapping quantitative trait loci controlling cool-temperature tolerance at the booting stage in temperate japonica rice. Breed. Sci. 51: 191-197.

Thomashow MF 1999 Plant cold acclimation: freezing tolerance genes and regulatory mechanisms. Ann. Rev. Plant Physiol. Plant Mol. Biol. 50: 571-599.

Visperas RM and Vergara BS 1981 Correlation of cold tolerance at different growth stages in rice. Acta Botanica Sinica. 23-2: 203-207.

Wu RJ, Ho and THD, 1999, Production of water stress or salt stress tolerant transgenic cereal plants, US patent issued on NovemberDecember 9, http://www.docstoc.com/docs/ 52272202/Production-Of-Water-Stress-Or-SaltStress-Tolerant-Transgenic-Cereal-Plants--Patent-5981842 last browsed on 22.11.2011

Yan CYX, Li ZK, Cheng HX, Yu MH, Gu and Zhu LH 1999 Identification of QTL for cold tolerance at early seedling stage of rice (Oryza sativa L.) via RFLP markers. Chin. J. Rice Sci. 13 -3: 134-138.

Yoshida S 1981b Fundamentals of rice crop science. Growth and development of the rice plant, Los Banos: IRRI, cap.1: 1-63.

Zhang ZH, Qu X-S, Wan S, Chen LH and Zhu YG 2005b Comparison of QTL controlling seedling vigor under different temperature conditions using recombinant inbred lines in rice (Oryza sativa L.). Annals of Botany.95: 423 $-429$.

Zhang ZH, Su L, LiW, Chen and Zhu YG 2005a A major QTL conferring cold tolerance at the early seedling stage using recombinant inbred lines of rice (Oryza sativa L.). Plant Sci. 168: 527-534.

Zhi HL, Yuan ZY,Li QY,Lan CG, Yuan ZS, Hwan KJ and Jong KH 2006 Genetic and QTL analysis for low-temperature vigor of germination in rice. Acta Genetica Sinica. 3311: 998-1006. 